\title{
De barones y barrigones: el periplo de las esculturas de Concepción, Escuintla
}

\section{Of Barons and Potbellies: The Long Journey of the Sculptures from Concepción, Escuintla}

\author{
Oswaldo Chinchilla Mazariegos \\ Yale University \\ Marie-France Fauvet-Berthelot \\ Musée de l'Homme
}

\begin{abstract}
Resumen: Las esculturas monumentales conocidas como "barrigones" forman un género distintivo en el arte prehispánico del sur del área maya. En este artículo se explora la procedencia e historia de tres barrigones que se encuentran en museos de Alemania y Francia, y que fueron extraídos de la finca Concepción, Escuintla, Guatemala, en el siglo XIX. Por medio del estudio de documentos inéditos se demuestra que provienen del mismo sitio arqueológico y se corrigen los errores de trabajos anteriores, que los atribuyeron a otros sitios e incluso a otras regiones. Se resumen las actuaciones y motivaciones de tres individuos (un terrateniente, un diplomático y un arqueólogo) que participaron en esa apropiación, que ilustran los procesos económicos, políticos e intelectuales que determinaron la suerte de las esculturas. Estas conclusiones permiten entender mejor la distribución geográfica de los barrigones y forman un aporte a la historia de la arqueología en Guatemala.
\end{abstract}

Palabras Clave: Historia de la arqueología, Guatemala, Escuintla, escultura, barrigones.

ABSTRACT: The monumental sculptures known as "barrigones" (potbelly sculptures) form a distinctive genre of Pre-Columbian art in the southern Maya area. In this article, we explore the provenance and history of three sculptures that were extracted in the nineteenth century from finca Concepción, Escuintla, Guatemala, and taken to museums in Germany and France. Through the study of unpublished documents, we demonstrate that they originated from a single archeological site, and correct mistakes in previous works, which attributed them to other sites and even other regions. We summarize the role and motivations of three individuals (a landowner, a diplomat, and an archaeologist) who participated in the sculptures' appropriation, who illustrate the economic, political, and intellectual processes that determined the fate of the sculptures. Our conclusions allow a better understanding of the genre and contribute to the history of archaeology in Guatemala

KEYwORDs: History of archaeology, Guatemala, Escuintla, sculptures, potbellies.

RECEPCIÓN: 31 de mayo de 2017.

ACEPTACIÓN: 20 de junio de 2017.

DOI: 10.19130/iifl.ecm.2018.52.914. 
En 1886 llegó a Francia, seguramente por el puerto de Saint-Nazaire, una escultura de piedra procedente de Guatemala (Figura 1). Desde el puerto sobre el Loira, la escultura viajó por tren hasta el castillo de Baye, a 120 km de París, cerca de la ciudad de Épernay, famosa por su champaña.

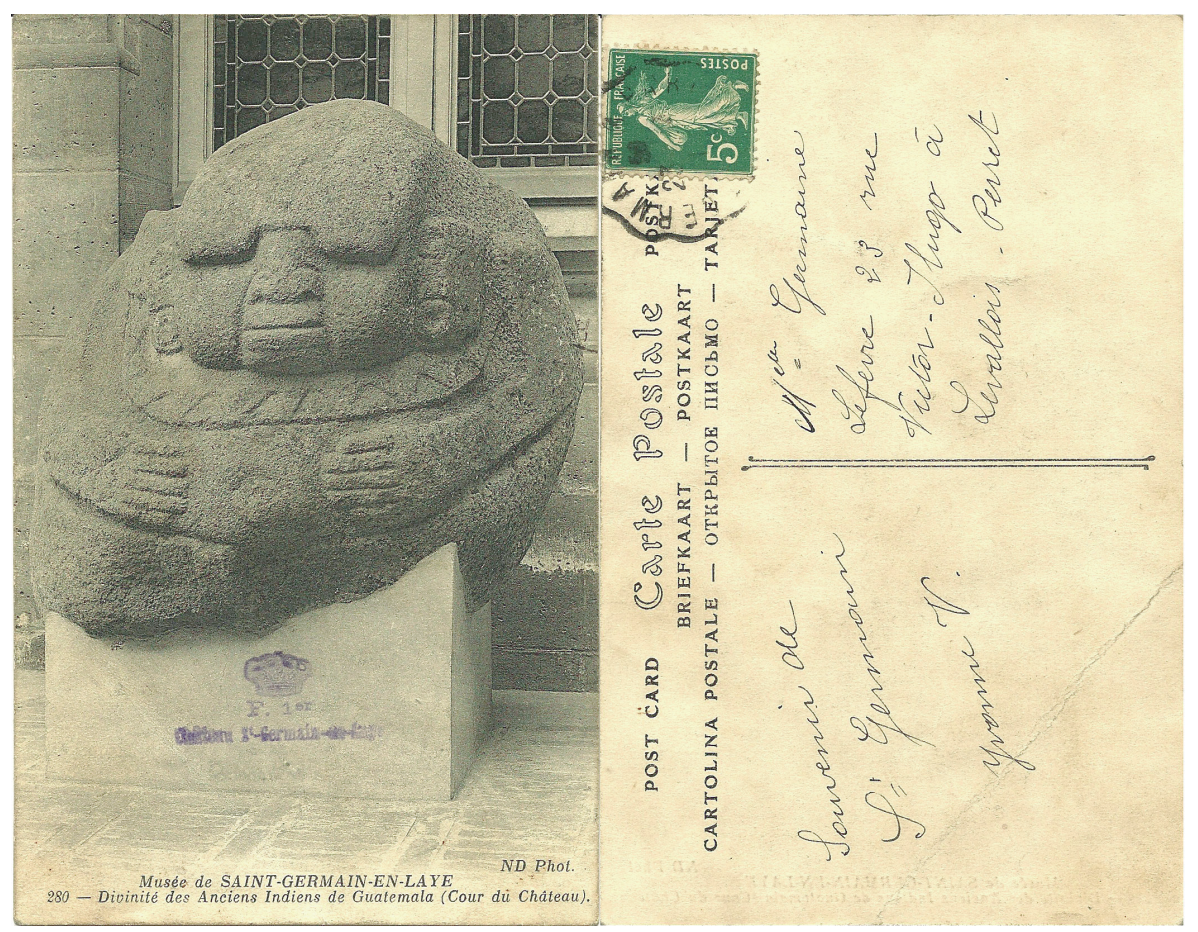

Figura 1. Tarjeta postal del Museo de Saint-Germain-en-Laye, que muestra al barrigón de Concepción, identificado como "Divinidad de los antiguos indios de Guatemala (patio del castillo)", anverso y reverso.

Tallada en una roca de canto rodado, apenas modificada para representar una figura humana, la escultura pertenece al género que actualmente se conoce como "barrigón”, ampliamente diseminado en la Costa Sur y el Altiplano Central de Guatemala (Guernsey, 2012; Rodas, 1993). Como otras de este género, se caracteriza por su aspecto rollizo. Pesa 1,371 kilos, mide $110 \mathrm{~cm}$ de alto y $112 \mathrm{~cm}$ de diámetro, y representa un personaje de cuerpo entero, sentado, con las piernas apenas esbozadas. La cabeza achatada está pegada al torso, sin cuello alguno. La cara mofletuda del personaje, con los ojos cerrados por párpados pesados, se corresponde con su obesidad. Por todo adorno lleva orejeras discoidales y un collar decorado con un diseño en zigzag. Orondo, sus brazos reposan sobre la 
panza voluminosa. Las manos quedan a los lados del ombligo saltón, marcado por un círculo amplio. La talla es tridimensional, pero el lado posterior está casi en bruto.

Hoy en día, el barrigón se conserva en las bodegas del Museo del Quai Branly, en París, correctamente identificado como procedente de Concepción, Escuintla (Mapa 1). Pero ¿cómo llegó hasta allá, y qué sabemos sobre su lugar de origen? En las siguientes líneas trazaremos la historia de éste y otros dos barrigones que formaron parte del mismo conjunto. Los tres fueron a parar a museos europeos, como consecuencia de procesos que marcaron la historia de Guatemala en la segunda mitad del siglo xix: la integración económica del país en los mercados mundiales y el auge de la caficultura, que corrieron parejas con la presencia creciente de inmigrantes e inversionistas de varios países europeos. En el ámbito intelectual, estos procesos redundaron en un interés por la etnografía y la arqueología, pero, a la vez, estimularon el coleccionismo de objetos arqueológicos que nutrió las salas y las bodegas de los grandes museos, escaparates que hicieron pública la hegemonía de las potencias europeas en el mundo.

La historia de los barrigones de Concepción involucró a tres hombres representativos de estos procesos históricos: el barón du Teil (*1827 - †1879), empresario agrícola y aficionado a la arqueología de Guatemala; el barón de Baye (*1853 - †1931), aristócrata, coleccionista y pionero de los estudios etnográficos, y Werner von Bergen ("1839 - †1901), representante diplomático del imperio alemán en Centroamérica. En las siguientes páginas trazaremos breves perfiles de estos personajes y reconstruiremos el periplo de los barrigones, desde la cálida bocacosta de Guatemala hasta los vastos museos de París y Berlín.

\section{El barón du Teil y el sitio de Concepción}

Según el historiador Ralph Lee Woodward (1993: 385), los miembros de la familia du Teil (o du Theil) llegaron a Guatemala durante el experimento de colonización belga en Izabal, en la década de 1840. Sin embargo, la familia era del sur de Francia, vieja nobleza oriunda de la Provenza. Un antepasado, el General Jean-Pierre du Teil, tuvo como alumno a Bonaparte, el futuro Napoleón I, en la Real Escuela Militar de Auxonne, en Borgoña, entre 1788 y 1791. El infortunado general fue fusilado durante la revolución, pero el emperador no lo olvidó. Desde su exilio en Santa Helena, legó por testamento a su hijo o nieto la suma de cien mil francos "en memoria de gratitud por el cuidado que ese valiente general tuvo con nosotros cuando fuimos teniente y capitán bajo sus órdenes” (Jougla de Morenas, 1949). ${ }^{1}$

\footnotetext{
${ }^{1}$ Testamento de Napoleón, cuarto codicilio, primera cláusula: Nous léguons au fils, ou petit-fils du baron Du Teil, lieutenant général d'artillerie, ancien seigneur de Saint-André, qui a commandé l'école d'Auxonne avant la Révolution, la somme de 100000 (cent mille francs) comme souvenir de reconnaissance pour les soins
} 


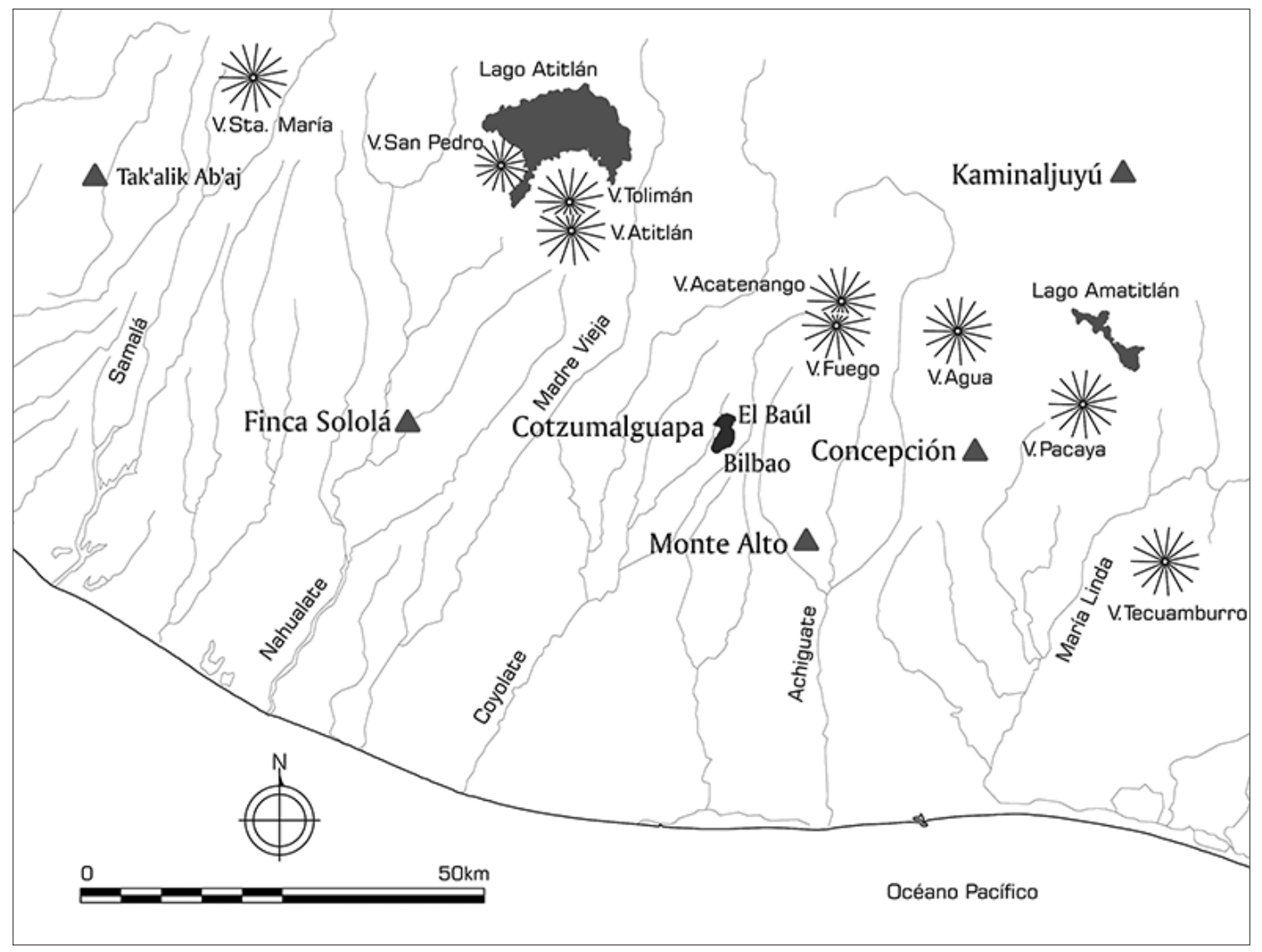

Mapa 1. Mapa de la Costa Sur de Guatemala, con la localización de los sitios mencionados en el texto. Dibujo: Oswaldo Chinchilla.

Un biznieto del general, el barón Joseph-Césaire-Oscar du Teil emigró a Guatemala en 1851 y se casó con doña María Palomo de Rivera y Batres, de familia criolla prominente (Figura 2; Révérend, 1902: 514). Con su hermano, JosephPierre-Marie-Xavier du Teil (*1831 - †1900), desarrolló una próspera plantación de café —una de las primeras en el país— en su finca Concepción, cerca de Escuintla (Wagner, 2001: 43-44). En 1866, los hermanos du Teil describieron sus experiencias como caficultores pioneros en una instrucción titulada "Cultivo del cafeto y beneficio de su fruto", publicada en tres entregas en la publicación periódica La Sociedad Económica de Guatemala. Los du Teil eran miembros de esa entidad y, a la vez, se presentaban como miembros de la Sociedad Imperial Zoológica de Aclimatación de París. En 1867 establecieron la primera compañía telegráfica en Guatemala y también se involucraron en el proyecto de fundación de un banco nacional (Woodward, 1993: 366, 574).

que ce brave général a pris de nous, lorsque nous étions lieutenant et capitaine sous ses ordres (Baring-Gould, 1897: 606). 


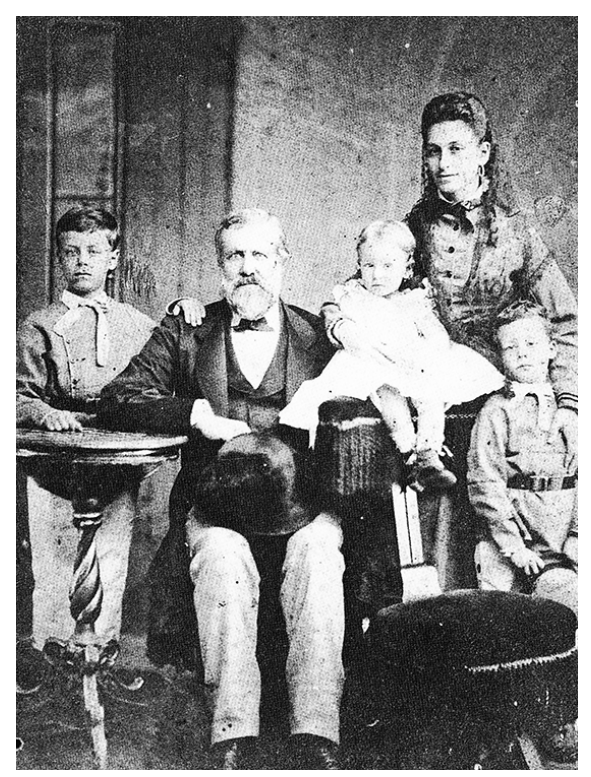

Figura 2. El barón Oscar du Teil con su familia. Tomado de Wagner, 2001: 44, reproducida con autorización.

Más interesante para este artículo fue el nombramiento del barón Oscar du Teil, por decreto del 10 de agosto de 1864, como corresponsal de la Comisión Científica en México, creada con motivo de la expedición militar de Napoleón III (1862-1867). Esa comisión, compuesta por científicos de diferentes campos, tenía como meta reunir documentación sobre México y Centroamérica, en particular sobre sus habitantes autóctonos. El barón du Teil compartió este nombramiento con monseñor Francisco de Paula García Peláez (*1785 - †1867), historiador y arzobispo de Guatemala (LeGoff y Prevost, 2009: 13). El nombramiento refleja la reputación del barón como interesado por las ciencias y entre ellas, la arqueología.

Debió ser hacia 1860 cuando el barón du Teil tuvo noticia de los barrigones. El informe debió venir de los trabajadores que se ocupaban de despejar la tierra para sembrar el arbusto exótico del café, que habría de transformar sus vidas y las de sus hijos, desde entonces integradas en el aparato formidable de la economía mundial. El barón no escribió noticia alguna sobre el hallazgo, pero, al parecer, hizo llevar un barrigón al Museo de la Sociedad Económica, establecido en 1866 en la ciudad de Guatemala (en el domicilio que actualmente ocupa el Congreso de la República, en la 9a avenida, entre 9a y 10ª calles, zona 1). Allí lo vio el etnógrafo alemán Adolf Bastian, en 1876:

El señor barón du Theil, quien ya estuvo activo para Brasseur de Bourbourg, me informó sobre los hallazgos de antiguiedades en su propiedad, y una antigua figura

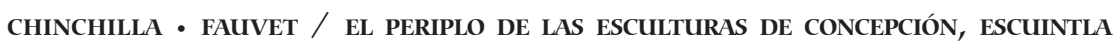


de piedra, que fue traída de su cercana hacienda a la ciudad, se encuentra en el patio del museo, colocada en una esquina (Bastian, 1878: 385).

La descripción es escueta, y no provee información sobre la forma de la escultura ni la figura que representaba, pero se puede suponer que era uno de los barrigones, probablemente el que llegó a Francia 10 años después. La Sociedad Económica fue clausurada en 1881 , y la colección del museo pasó al Instituto Nacional (Chinchilla, 2016; Luján, 1973). Es probable que entonces los du Teil hayan reclamado la escultura. El barón Oscar du Teil había muerto en 1872, y el título pasó a su hijo Louis, con apenas cuatro años (Révérend, 1902: 514). Al parecer, fue su hermano Xavier quien tomó las riendas de los negocios familiares por algún tiempo. Aunque no heredó el título nobiliario, Xavier aparece como barón en la correspondencia de Werner von Bergen, el embajador alemán, que adquirió de él las esculturas que actualmente se encuentran en Berlín.

\section{Werner von Bergen y las esculturas de Berlín}

En carta fechada el 9 de mayo de 1885, Bergen informó al Museo Etnológico de Berlín que por fin había logrado remitir 20 piedras de la región de Santa Lucía Cotzumalguapa. El próximo barco de la línea naviera Kosmos llevaría “dos piedras muy valiosas -ídolos - los cuales fueron excavados en La Concepción, cerca de Escuintla, que atrajeron al Profesor Bastian de modo muy especial, y que ahora su propietario, el barón Havier du Theil da como donación al museo". ${ }^{2}$ En efecto, las dos piedras fueron embarcadas en el vapor Menes, y arribaron a Hamburgo en septiembre del mismo año.

Friedrich Ludwig Werner von Bergen dedicó su vida al servicio del imperio alemán. Los datos que tenemos sobre su familia son escuetos, pero parece que también él disfrutaba del título de "barón”. Así se le nombra en algunos textos de la época (Bergen y Smith, 1975; United States Congress House, 1898: 335). Estudió derecho por dos años (1855-57) antes de ingresar al ejército, donde alcanzó el grado de capitán, pero se retiró de la milicia a consecuencia de padecimientos derivados de su participación en la guerra austro-prusiana de 1866. Ingresó al servicio diplomático, y fue secretario en Caracas, donde contrajo matrimonio. Luego sirvió como cónsul ante Chulalongkorn, rey de Siam (1871-74), y cónsul general en Saigón (1874-76). A partir de 1876, pasó a ser Ministro General y Encargado de Negocios en Centroamérica, con sede en la ciudad de Guatemala, y desempeñó diversos cargos en el país hasta $1897 .^{3}$

\footnotetext{
${ }^{2}$ Archivos del Ethnologisches Museum, Berlín, Alemania. Acta Betreffend die Steinsculpturen von Santa Lucia Pars I B. Litt E, hoja 1544/84.

${ }^{3}$ Datos biográficos tomados de Wikipedia, 2016.
} 
En sus actuaciones diplomáticas, Bergen representó activamente la política del canciller alemán Bismarck, tendiente a promover la supremacía alemana en la vida económica y política de Centroamérica. Apenas instalado en su puesto, jugó un papel protagónico en el incidente Eisenstück, que se inició como una disputa personal entre un oficial del gobierno nicaraguiense y dos ciudadanos alemanes, y creció hasta convertirse en un asunto diplomático. El gobierno alemán aprovechó la disputa para demostrar su capacidad de intervención y destacó seis barcos armados, cuyas tropas desembarcaron en el puerto de Corinto en 1878. El gobierno nicaraguiense fue obligado a pagar una indemnización y saludar la bandera alemana (Schoonover, 1998: 74). En 1880, el ministro de asuntos exteriores guatemalteco, Lorenzo Montúfar, se quejó ante el gobierno alemán de "la hostilidad de su representante, su carácter irritante, y la magnitud del placer que obtiene ofendiendo", y agregó que Bergen censuraba "al presidente, al gabinete, a quienes apoyaban al gobierno, las leyes, y a quienes las dictaban". ${ }^{4}$ Repetidas veces acusó públicamente a los Estados Unidos por sus ambiciones imperiales en la región, al punto que el secretario de Estado de esa nación solicitó una explicación al gobierno alemán (Schoonover, 1998: 79). Además de cumplir sus misiones diplomáticas, Werner von Bergen no dejó de interesarse por aspectos de la cultura y la lengua de los pueblos que conoció. Notablemente, fue coautor de un tratado sobre los verbos pasivos en la lengua siamesa (Bergen y Smith, 1875).

Este fue el personaje que envió a su país las esculturas de Concepción. La iniciativa del diplomático formaba parte de un proyecto más ambicioso: la adquisición de una amplia colección de esculturas de Santa Lucía Cotzumalguapa, idea acariciada por Adolf Bastian, director de la sección etnológica de los Museos Reales de Berlín, desde su visita a Guatemala en 1876. Guatemala fue una de las últimas escalas de un largo viaje, en el que Bastian visitó Chile, Perú, Ecuador y Colombia (Fischer, 2007). En cada país, adquirió colecciones etnográficas y arqueológicas destinadas a engrosar los acervos del Museo Etnológico de Berlín. Amasar especímenes representativos de todas las épocas y todas las culturas era un objetivo primordial del museo, que Bastian concebía como un vasto repositorio de objetos de estudio que demostrarían la unidad fundamental de la especie humana y permitirían estudiar todas sus variaciones (Penny, 2002: 18-23; 2003).

Bastian quedó impresionado con los monumentos de Cotzumalguapa e inmediatamente hizo arreglos para adquirirlos, pero sus esfuerzos se retrasaron por una serie de circunstancias que incluyeron el inesperado fallecimiento del connotado americanista Carl Hermann Berendt, que había sido contratado para supervisar la excavación y exportación de las esculturas, después de cortarlas en bloques de tamaño manejable (Chinchilla, 1996a). Muerto Berendt, no hubo quién se hiciera cargo del proyecto hasta 1879, cuando el embajador Bergen tomó cartas en el asunto. Entre 1881 y 1886 envió a Berlín cinco embarques con esculturas, la mayoría procedentes de Cotzumalguapa. Sin embargo, no desper-

\footnotetext{
${ }^{4}$ Citado en Schoonover, 1998: 77. Traducción del inglés por Oswaldo Chinchilla Mazariegos.
} 
dició la oportunidad de incluir ejemplares de otros sitios, como el Dintel 56 de Yaxchilán, que había sido extraído de aquel sitio y llevado a la ciudad de Guatemala por el cónsul Frans Sarg (Chinchilla, 1996a: 309-310).

A los dos barrigones enviados en 1885, Bergen añadió otra pieza de Concepción: una escultura con espiga vertical que representa un pájaro. Esta escultura salió en 1886 junto con los Monumentos 15 y 17 de Bilbao. Así lo afirma la nota de envío correspondiente:

"Piedra con el Aguila" y "Piedra con la escalera" además una piedra con un ave parada sobre una columna (proviene de las propiedades del barón X du Teil cerca de Escuintla). ${ }^{5}$

El viaje no fue enteramente feliz. La "piedra con el águila” —el Monumento 17 de Bilbao- cayó al mar durante el embarque en el puerto de San José, Escuintla (en el litoral Pacífico de Guatemala), y nunca fue recuperada. Solo llegó a Berlín un fragmento, que había sido cortado para facilitar el traslado (Chinchilla, 1996a: 310).

Esta pérdida no hizo amainar la curiosidad arqueológica del enérgico ministro. En carta fechada el 17 de noviembre de 1886 (Anexo I), notificó que el barón du Teil había autorizado la "explotación” del sitio arqueológico en el que se habían encontrado la "estatua del pájaro" y los "dos grandes ídolos” que ya estaban en Berlín. Es probable que no lograra los 1500 marcos que requería para iniciar la tarea o, si los obtuvo y realizó la "explotación”, quizá se vio frustrado en el intento de hallar más esculturas. No hay noticia de que haya enviado otras a Berlín después de esta fecha.

\section{El barón de Baye y el barrigón de París}

Suponemos que a Werner von Bergen le debió doler la decisión del barón du Teil, que optó por no enviar a Alemania el tercer barrigón de Concepción —probablemente el que antes estuvo en el Museo de la Sociedad Económica - sino a su amigo, el barón de Baye, en Francia (Figura 3). ¿Quién era Amour-Auguste-Louis Joseph Berthelot, barón de Baye y conde de Saint-Laurent?

La familia Berthelot, noble y oriunda de Bretaña, enraizada en la región de Champagne desde el siglo xvII, se instaló en el castillo de Baye en el Marne a principios del siglo xvIII (Figura 4). Nacido en 1854, el barón se interesó desde muy joven por la arqueología de la región. Condujo excavaciones alrededor de sus propiedades, encontrando cuantiosos vestigios de diferentes épocas, e instaló un museo en el primer piso de su castillo. De mente curiosa, le interesaba

\footnotetext{
${ }^{5}$ Archivos del Ethnologisches Museum, Berlín, Alemania. Acta Betreffend die Steinsculpturen von Santa Lucia Pars I B. Litt E. Sin paginación.
} 

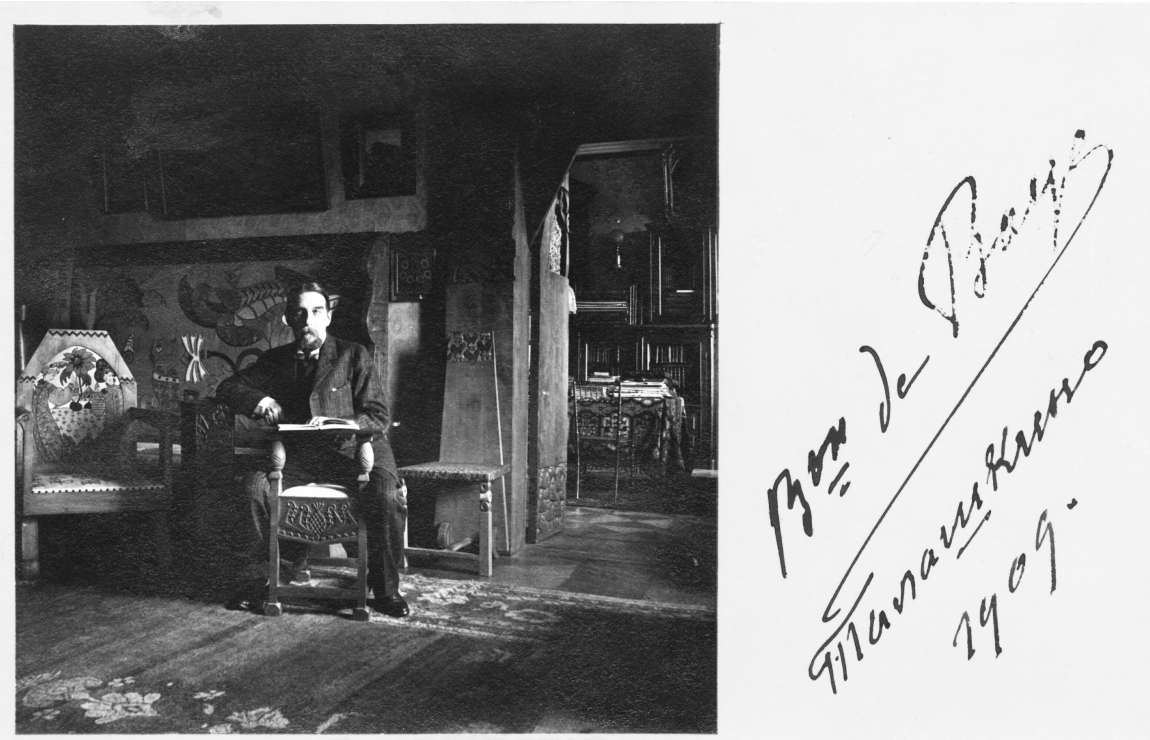

Figura 3. Joseph Berthelot, barón de Baye.

Foto: Musée du Quai Branly, París, inventario PPO098762.

sobre todo el llamado "arte bárbaro" en Europa, relacionado con las migraciones de los pueblos germánicos entre los años 300 y 900 de nuestra era (Baye, 1880; 1893). A partir de la década de 1890 pasó largas temporadas en Rusia haciendo excavaciones, coleccionando objetos etnográficos y tomando muchas fotografías. Fue miembro de varias sociedades científicas europeas y dejó una impresionante bibliografía con más de 150 títulos. Donante generoso, enriqueció el patrimonio de diversos museos y bibliotecas especializadas en Francia.

Aunque no enfocó sus estudios en el Nuevo Mundo, el barón de Baye mantuvo un interés por el continente. Fue miembro de la Sociedad de Americanistas desde su creación en 1896, aunque su nombre no aparece más como socio a partir de 1903. Participó en siete Congresos Internacionales de Americanistas en Europa, entre 1883 y 1904, a veces como miembro del consejo. Entre otros temas americanos, se interesó por la trepanación de cráneos, el origen de los objetos en jade y las posibles relaciones con Asia.

Poco sabemos sobre su relación con el barón du Teil e ignoramos cómo se gestó el asunto del barrigón. En el Museo de Épernay se conserva la copia de una carta fechada el 3 de marzo de 1885, en la cual el barón de Baye expresaba cuán feliz le haría recibir el ídolo que su amigo le proponía. Expresaba gran interés por la arqueología de América Central, "materia aún tan poco conocida", y le agradecía toda la información y los objetos que pudiera enviarle (Anexo II).

El barrigón permaneció 20 años en el castillo de Baye, de 1886 a 1906 . No sabemos dónde estuvo, quizás en el patio interior del castillo o cerca de la fachada

CHINCHILla - FAuVET / EL PERIPLO de LAS ESCULTURAS DE CONCEPCión, ESCUINTLA 


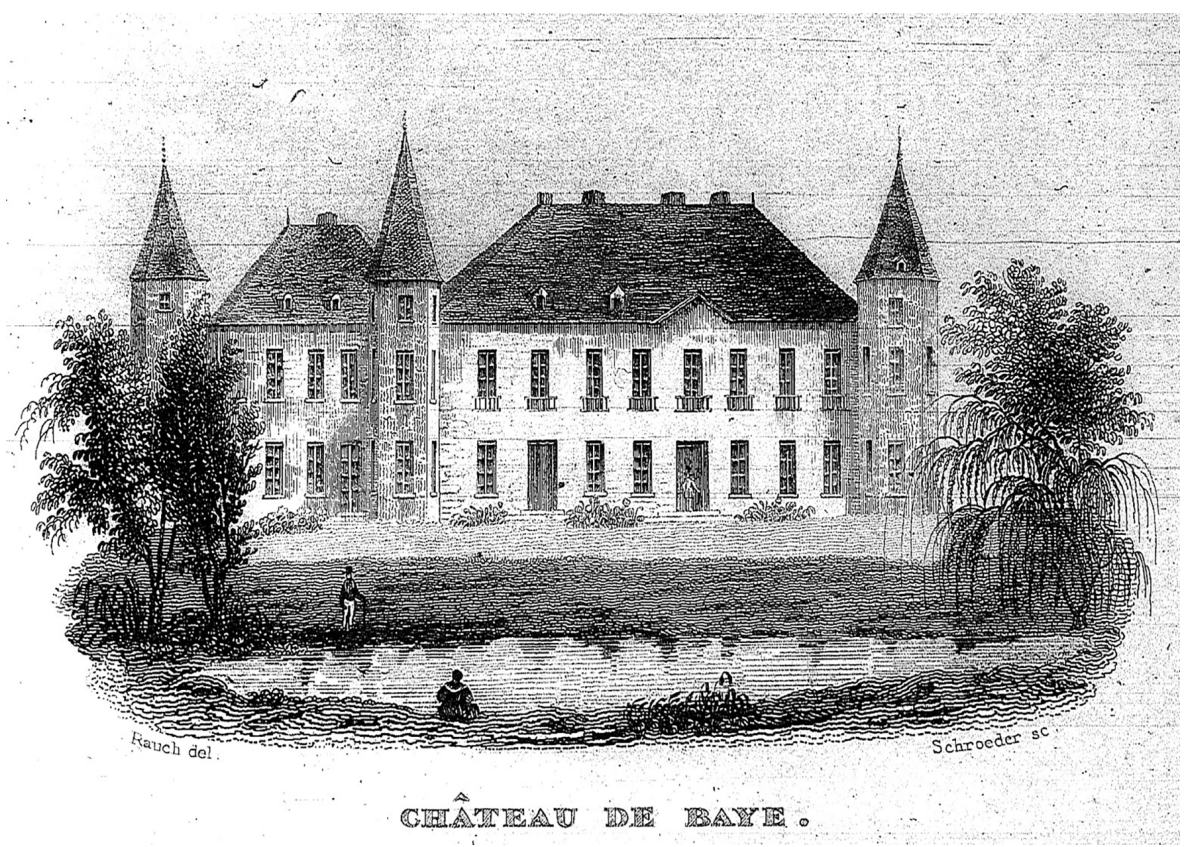

Figura 4. El castillo de Baye, Francia. Grabado de 1838. Ilustración de dominio público.

principal, donde seguramente lo veían todos los visitantes del museo arqueológico instalado en el primer piso. Afectado por serios problemas familiares, el barón de Baye decidió ceder su museo particular al Museo Arqueológico Nacional, creado en 1862 por Napoleón III cerca de París, en el castillo de Saint-Germain-enLaye. Así lo anotó en su agenda, el 20 de mayo de 1905: "Parece que antes de mi muerte, sea yo mi propio albacea”. La donación se realizó el 1 de diciembre de 1906 y quedó ratificada por decreto el 25 de abril de 1907. La colección, cuyo valor se estimó en 12,000 francos, se compone de 556 objetos arqueológicos europeos además del barrigón, que quedó anotado en la última hoja del inventario: "un coloso de piedra de Guatemala estimado en seiscientos francos". 6 Por segunda vez, el barrigón recorrió Francia, esta vez hacia el oeste, para quedar instalado en el patio del castillo de Saint-Germain-en-Laye. En este sitio, el barrigón fue un icono distintivo, como lo prueban varias series de tarjetas postales que lo muestran frente a una ventana con pequeños cristales, característica del siglo XVI (Figura 1).

\footnotetext{
${ }^{6}$ Archives des Musées Nationaux, París, G8 1907, Donation Baron de Baye au Musée de Saint-Germain.
} 
A pesar del deseo, claramente expresado en el acta de donación del barón de Baye, de que no se desparramara su colección, el barrigón fue trasladado el 29 de julio de 1938 al Museo del Hombre, recién abierto en París. Este museo reemplazó al Museo de Etnografía del Trocadero, creado en el mismo lugar en 1878. Sin duda, el traslado se consideró apropiado porque allí se encontraban las colecciones de arqueología y etnografía americana. Quizá por primera vez el barrigón quedó bajo techo en la galería americana del primer piso, junto con otras esculturas monumentales de piedra de varias regiones del continente americano. En 1965 formó parte de la exposición Obras maestras del Museo del Hombre, en el mismo museo, y, en 2002, viajó a Madrid para la exposición El país del quetzal: Guatemala maya e hispana (Sociedad Española para la Acción Cultural Exterior, 2003: 248-249). Su viaje más reciente fue en 2004, cuando atravesó el Sena para integrarse a la colección del Museo del Quai Branly, recientemente inaugurado en París. Desgraciadamente, no quedó expuesto al público y se guarda en la "reserva de objetos de grandes dimensiones".

\section{Enredos y desenredos}

Tan voluminosos como el vientre de los barrigones han sido los enredos que se han generado sobre su procedencia e identificación. Quizá su aspecto austero y su expresión enigmática han abierto las puertas para una variedad de especulaciones poco informadas. El primero que trató de entenderlos fue el propio barón de Baye. Enterado de que los otros dos barrigones de Concepción paraban en Berlín, escribió al director de aquel museo, el 8 de abril de 1886, una carta donde solicitaba información sobre ellos, acompañada con un dibujo del barrigón (Anexo III y Figura 5). No se conoce respuesta, pero en una segunda carta, el 20 de agosto del mismo año, el barón agradeció un folleto que había recibido, relativo a las piedras esculpidas de Guatemala, en el que, sin embargo, no encontró nada relacionado con "el ídolo indiano" que él poseía. El folleto debió ser Steinsculpturen aus Guatemala, obra publicada por Bastian en 1882, cuyo único valor fue reproducir secciones de las cartas escritas por el finado Berendt durante su estancia en Santa Lucía Cotzumalguapa.

Poco después, el barón presentó un dibujo del "ídolo" en el Congreso Internacional de Americanistas, en Turín. En una nota publicada en el acta de la tercera sesión del congreso, informó acerca de la procedencia, las dimensiones y el peso del monumento, añadiendo que estaba hecho de roca volcánica, común en la región. A manera de interpretación, comentó:

Los indios, antiguos habitantes de la región, creían en un Dios supremo quien dejaba el gobierno del mundo a unos genios de orden inferior, representados por extrañas figuras. Un respeto religioso conservó para cada ídolo un tipo individual que no se permitía modificar. En esas condiciones, a pesar del progreso de la es-

CHINCHILla - FAuVET / EL PERIPLO de LAS ESCULTURAS DE CONCEPCión, ESCUINTLA 
cultura, el culto perpetuó las formas groseras de los ídolos (Congrès International des Américanistes, 1886: 31-32). ${ }^{7}$

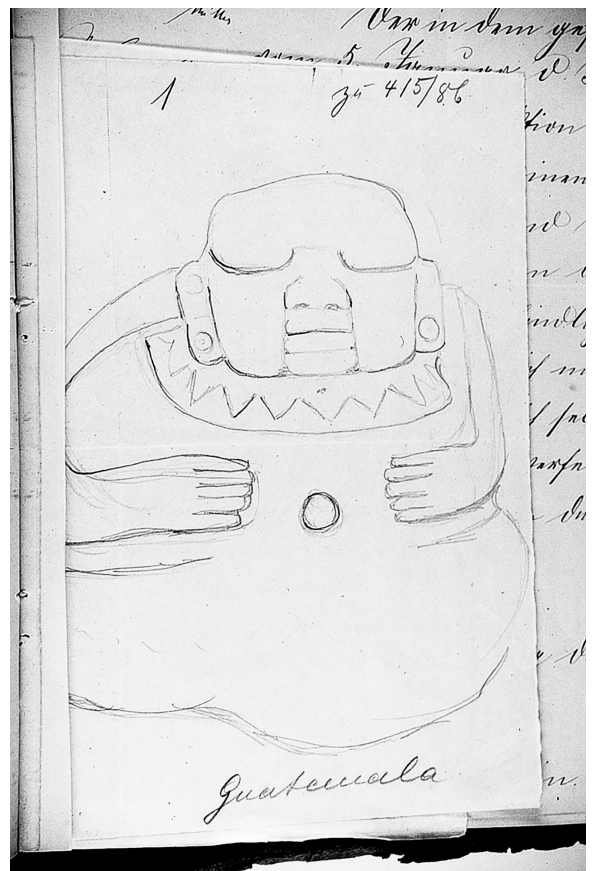

Figura 5. Dibujo del barrigón, por el barón de Baye, adjunto a su segunda carta a Adolf Bastian (Anexo II). Fotografía: Oswaldo Chinchilla Mazariegos.

Obviamente, la estética del barrigón no era del agrado del barón de Baye. Otro participante en esta sesión del congreso, el connotado americanista Eduard Seler, aclaró que "el ídolo tan interesante, no se corresponde con el arte que se conoce de la región de donde proviene" (Congrès International des Américanistes, 1886: 31-32). Seler trabajaba desde 1884 en el Museo Etnológico de Berlín, pero su respuesta nos hace pensar que no conocía aún los dos monumentos que Bergen había remitido allá. Terció en la discusión Désiré Charnay, quien afirmó haber encontrado en México un ídolo análogo al del barón de Baye, aunque más pequeño, y añadió: "tienen, uno y otro, un mismo origen" (id.).

Al parecer, los americanistas de la época tuvieron dudas sobre el origen costeño del barrigón y, comenzando con Charnay, le buscaron analogías en otras regiones. Sobre su procedencia no había duda, y las tarjetas postales del Museo Arqueológico de Saint-Germain-en-Laye lo identificaban como "Divinidad de los antiguos indios de Guatemala". Pero sorpresivamente, en 1911 cambió de iden-

\footnotetext{
7 Traducido por Marie-France Fauvet-Berthelot.
} 
tidad y apareció en el inventario manuscrito del Museo como "estatua de lava (tezontli) figurando seguramente a Coyolxanhqui [sic], la hermana de Huitzilopochtli, dios tribal de los mejicanos y su enemigo (véase E. Seler, 1901: 113137; reproducido en Gessamm. Abhandlungen II: 814)". ${ }^{8}$ Una nota en el margen del inventario especifica: "Donación de Baye (véase su colección, donación ya antigua; objeto muy pesado, colocado en el patio del Museo e identificado por Beuchat, julio de 1911)”. La nueva identificación se debe, pues, a Henri Beuchat, autor de un Manual de Arqueología Americana (1912) quien, quizá por los ojos cerrados de la escultura le encontró parecido con la cabeza de Coyolxauhqui, hallada en el recinto ceremonial de México. Así que, en 1911, la divinidad de los indios de Guatemala pasó a ser, de manera muy arbitraria, una diosa mexicana.

De allí en adelante, se le presenta bajo la denominación de "divinidad mejicana” en el catálogo ilustrado del Museo de Saint-Germain-en-Laye, redactado por su director, el arqueólogo Salomon Reinach (ediciones de 1917 y de 1926). En años posteriores, la escultura reapareció en varios libros franceses, entre otros, en el primer tomo del prestigioso tratado L'Art et l'Homme, de René Huyghe, publicado en 1957. Esta vez adoptó una nueva identidad, que sin duda refleja la fascinación por la recién descubierta civilización olmeca: "Méjico, región del golfo, estatua olmeca proveniente de Tabasco" (Huyghe, 1957, I: 111, figura 196). Esta obra alcanzó gran difusión, y quizá pudo influir en la caracterización de los barrigones de la Costa Sur como esculturas olmecas, la cual se popularizó en Guatemala por medio de los trabajos de Rafael Girard (1962; 1968).

El barrigón recuperó su verdadera identidad gracias a Henri Lehmann, responsable del Departamento de América del Museo del Hombre. Al inicio de su carrera como americanista, colaboró en proyectos de exhibición en el Museo Etnológico de Berlín y, por tanto, pudo haber conocido los barrigones que allá se encontraban (Fauvet-Berthelot, 1992: 179). Más adelante, a partir de 1950, condujo investigaciones en Guatemala y, sin duda, conoció los barrigones de Monte Alto y de otros sitios de la Costa Pacífica. En el catálogo Chefs d'œuvre $d u$ Musée de l'Homme, Lehmann identificó al barrigón como "estatua antropomórfica, periodo Preclásico Tardío (300 años antes J.C.-250 años después J.C.). Guatemala - Finca de La Concepción cerca de Escuintla" (Musée de l'Homme, 1965: 170). Fue así como el barrigón de Concepción, en Francia por más de 120 años, cambió tantas veces de procedencia como de interpretaciones culturales.

Corrieron parecida suerte los dos barrigones que Werner von Bergen envió a Berlín. No hay indicación de que hayan recibido atención alguna por mucho tiempo. Al tenor del proyecto etnográfico de Bastian, los acervos del museo se multiplicaron desmesuradamente. El crecimiento fue tal que para la vuelta del siglo había alcanzado proporciones caóticas y se hacía imposible para los curadores mantener el orden y exhibir los objetos en la forma deseada (Penny, 2003). Los barrigones de Concepción entraron a formar parte de este gran proyecto de

${ }^{8}$ Archivo del Museo de Saint-Germain-en-Laye, Francia. DT 38-60. 
etnografía comparada pero, al parecer, compartieron la suerte de muchos objetos procedentes de todo el mundo, que se acumularon en el Museo Etnológico de Berlín en aquella época, pero quedaron inaccesibles para los investigadores y el público interesado. A pesar del interés del barón de Baye por averiguar sobre ellos, los barrigones fueron relegados al olvido por varias décadas.

Es poco probable que hayan sido exhibidos antes de la Segunda Guerra Mundial, pero, al menos, no se perdieron durante esa debacle. El museo, situado en el centro de Berlín, quedó severamente dañado por los bombardeos aliados. Sus colecciones fueron resguardadas, pero no sin que se perdieran objetos de gran valor, entre ellos el Dintel 56 de Yaxchilán y muchos objetos menores. Los barrigones de Concepción sobrevivieron, y pasada la guerra fueron trasladados, con el resto de la colección, a una instalación provisional del museo en Dahlem, al suroeste de Berlín. En 1970 se inauguró el nuevo edificio de dicho museo, y los barrigones quedaron expuestos en la primera sala, junto a las esculturas de Cotzumalguapa.

En alguno de esos movimientos se debió traspapelar la información sobre el origen de los barrigones y se les empezó a considerar como parte de la gran colección de esculturas de Cotzumalguapa. El causante del error debió ser Walter Krickeberg, americanista y director del museo, notorio por sus actuaciones discriminatorias durante el régimen nacionalsocialista en Alemania (Jell-Bahlsen, 1985: 322-323). En una guía publicada en 1950, Krickeberg ilustró por primera vez uno de los barrigones, pero lo atribuyó a Cotzumalguapa. Por entonces, afirma la guía, los dos barrigones flanqueaban el portal del museo (Krickeberg, 1950: 5).

Girard publicó fotografías de ambos en su libro Los mayas eternos y, sin más explicación, los atribuyó a Santa Lucía Cotzumalguapa. Además, los interpretó como representaciones de la deidad solar y del maíz, y los consideró como antecesores de las cabezas colosales de La Venta (Girard, 1962: 393-395, láminas 234-235). En un artículo publicado en 1965, Lee A. Parsons y Peter S. Jenson los reprodujeron nuevamente y los compararon con los barrigones de Monte Alto pero, en cuanto a la procedencia, fueron más allá que Girard y no dudaron en atribuirlos al sitio de Bilbao, un grupo arquitectónico monumental que durante el periodo Clásico formó parte del conjunto urbano de Cotzumalguapa, Escuintla (Mapa 1; Chinchilla Mazariegos, 2012). Parsons y Jensen supusieron que todas las esculturas de Cotzumalguapa en Berlín habían sido extraídas de Bilbao. Observaron el parecido con el barrigón de la finca Concepción que se hallaba en París, pero no por eso cayeron en cuenta de su error. En su reporte de investigación sobre Bilbao, Parsons les asignó números en la secuencia de esculturas de ese sitio. Así, los dos barrigones de Berlín se convirtieron en los monumentos 46 y 47 de Bilbao, mientras que el pájaro con pedestal vertical pasó a ser el monumento 68 de Bilbao (Parsons, 1969: 122, 128). El error se perpetuó en su obra sobre las esculturas preclásicas de Kaminaljuyú y la Costa Sur (1986: 43), y reapareció en el valioso catálogo de los barrigones de Escuintla, recopilado por Sergio Rodas (1993). 


\section{Los barrigones de Concepción}

Reunidos por fin —así sea en el papel- los tres barrigones por tanto tiempo separados (Figuras 1, 6 y 7), resta añadir un breve comentario sobre su procedencia y sus rasgos particulares. La separación injustificada acarreaba consecuencias importantes para la interpretación, no solo de este conjunto escultórico, sino de la distribución geográfica y los patrones de variación estilística que se perciben en este género de esculturas, que han sido esbozados en un trabajo anterior (Chinchilla, 2001-2002). Como no hay espacio en este artículo para una descripción de cada uno de los estilos regionales que se observan en lugares como Monte Alto, Kaminaljuyú, Santa Leticia o Tak’alik Ab’aj, baste decir que los barrigones de cada sitio presentan peculiaridades propias, y que los de Concepción forman uno de los conjuntos estilísticos más distintivos, con las siguientes características:

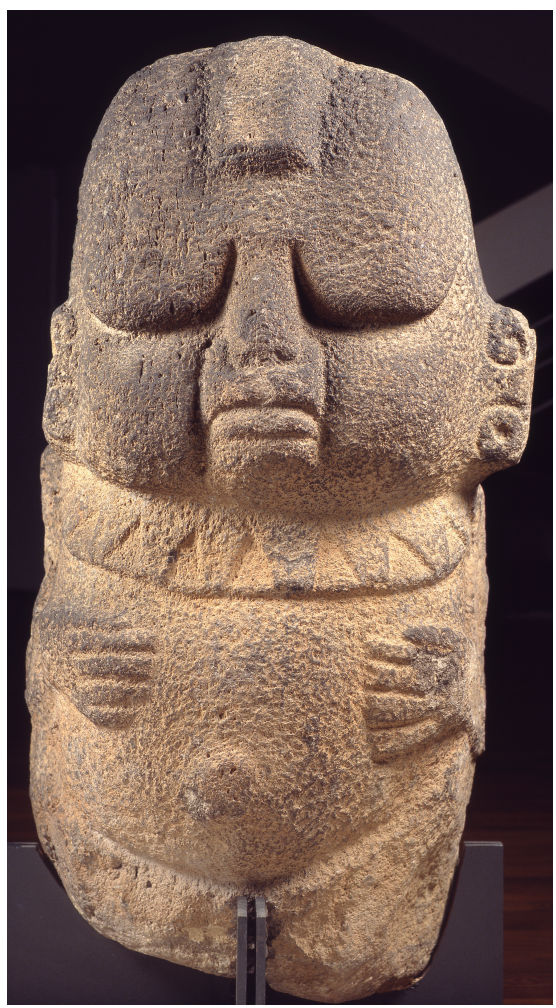

a

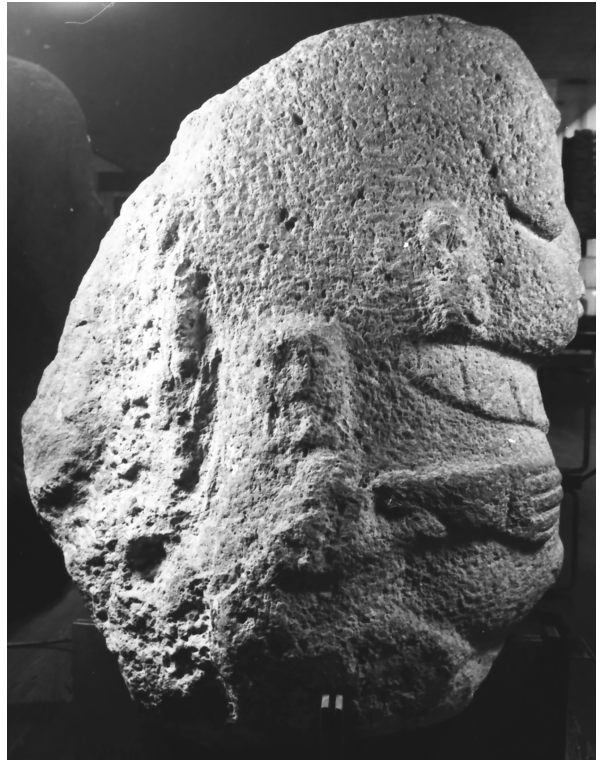

b

Figura 6. Barrigón en el Museo Etnográfico de Berlín, número de catálogo IV Ca 7197. Vista frontal y lateral. Fotografías: a) SMPK Museum für Völkerkunde, Berlín, cortesía de Marie Gaida; b) Oswaldo Chinchilla Mazariegos. 


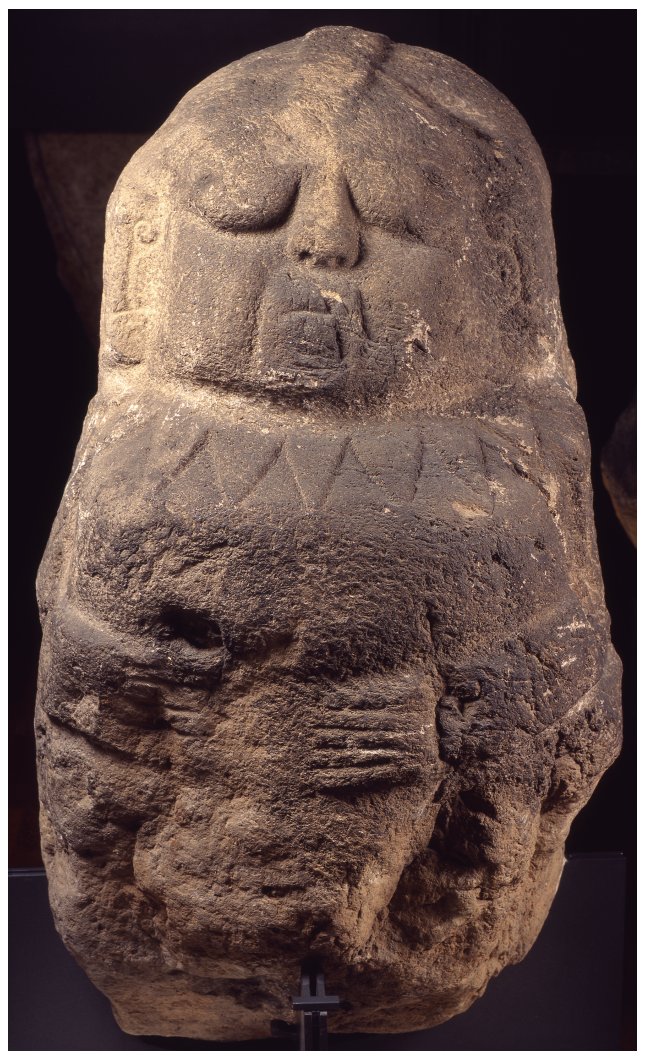

a

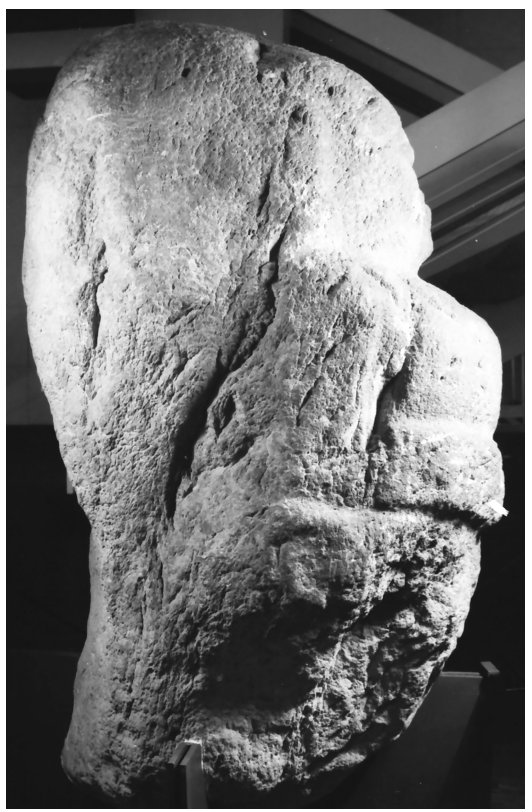

b

Figura 7. Barrigón en el Museo Etnográfico de Berlín, número de catálogo IV Ca 7196. Vista frontal y lateral. Fotografías: a) SMPK Museum für Völkerkunde, Berlín, cortesía de Marie Gaida; b) Oswaldo Chinchilla Mazariegos.

a) Conservan en gran medida la forma de las rocas de canto rodado en las que fueron labrados y su lado posterior fue dejado en bruto.

b) La cabeza es desproporcionadamente grande en comparación con el cuerpo. En el caso del barrigón de París, la proporción es 1:1. Los de Berlín presentan, respectivamente, proporciones de $1: 1$ y $1: 1.5$.

c) En comparación con los barrigones de Monte Alto o Kaminaljuyú, los detalles del rostro están labrados con más profundidad, de modo que el rostro aparece muy hinchado y los párpados son muy pesados.

d) Presentan una cresta en la cabeza, que corre desde el frente hacia atrás, apenas esbozada en el barrigón de París, pero muy notoria en los de Berlín.

e) Llevan orejeras pequeñas, circulares, y collares con diseño en zigzag.

f) El ombligo está claramente marcado por medio de un círculo sobresaltado.

g) Los brazos descansan sobre el vientre, con las manos rectas y los dedos extendidos.

h) No se ha prestado mayor atención a las piernas, que apenas están esbozadas en la base de las esculturas. 
La uniformidad de estilo de los tres barrigones hace pensar que fueron labrados en fechas cercanas entre sí y que formaban parte de un conjunto bien articulado. No sabemos dónde ni cómo estaban dispuestos originalmente, pero la comparación con otros conjuntos de barrigones nos permite suponer que pudieron estar alineados en algún conjunto arquitectónico importante. Se han documentado grupos de tres barrigones en los sitios de Santa Leticia, Tak'alik Ab'aj y la finca Sololá, Escuintla (Mapa 1). En los tres casos, los barrigones estaban alineados, frente a una escalinata en Tak'alik Ab'aj y sobre una plataforma en Santa Leticia (Demarest, Switsur y Berger, 1982; García, 1997; Parsons, 1986: 41).

Sabemos muy poco sobre los sitios arqueológicos situados en terrenos de la finca Concepción. Durante una excursión arqueológica a la Costa Sur, en 1942, Edwin Shook anotó las siguientes observaciones:

Finca Concepción - al oeste de la carretera y en la línea del tren. En la estación de ferrocarril de Concepción hay un sitio arqueológico moderadamente grande en una franja de terreno nivelado que domina la planicie costera del Pacífico. Posiblemente es el pueblo pipil de Escuintla (Izquintepec), de la época de la conquista. La línea del ferrocarril corta uno de los grandes montículos, y provee una buena oportunidad para obtener una muestra de cerámica del relleno del montículo (Shook, 1975: 13).

Lamentablemente, parece que Shook no se detuvo a recoger esa muestra y, hasta donde se sabe, no dibujó un plano ni dejó indicación sobre la cronología del sitio. Por su cercanía a la estación de tren, es muy probable que estos fueran los "cinco túmulos de los antiguos indios" a los que se refirió Werner von Bergen en su carta a Adolf Bastian (Anexo I), cerca de los cuales se encontraron los barrigones. En un trabajo anterior, este sitio casi desconocido fue designado con el nombre de Concepción-Estación para distinguirlo de Concepción-Cementerio, otro asentamiento localizado en el área del cementerio de la finca, del periodo Clásico Tardío, que fue registrado por Frederick Bove en 1981 (Chinchilla, 1996b: 487-490).

Actualmente, hay dos barrigones en el área de la antigua casa patronal de la finca Concepción (Figuras 8 y 9), además de dos asientos de piedra y una escultura de estilo Cotzumalguapa que representa al dios de la muerte. Sergio Rodas (1993: 12) reportó el Monumento 1, un barrigón que, según un informe recabado en 1994, proviene de un sitio que se localizaba en el cementerio de la finca. Chinchilla (1996: 487-490) denominó al lugar de procedencia de este barrigón como "Concepción-Cementerio". No se conocen detalles sobre tal sitio, ocupado por el cementerio moderno y las instalaciones de la finca. El segundo barrigón que actualmente se encuentra en dicho lugar (Monumento 4) parece corresponder al estilo del primero y quizá se haya originado en el mismo sitio.

El estilo de estos dos barrigones se aparta marcadamente de los tres que consideramos procedentes de Concepción-Estación. La relación entre la cabeza y el cuerpo es aproximadamente $1: 2$. El rostro está vuelto hacia arriba y las facciones 
son menos abultadas que las de los de Concepción-Estación. No tienen el ombligo saltón, les falta la cresta, las orejeras y el collar en zigzag que caracterizan a los encontrados en el siglo xIx. El Monumento 1 tiene la parte posterior tallada en su totalidad para formar la espalda del personaje. Aunque la información disponible sobre su procedencia es escasa, resulta claro que estos dos barrigones forman un grupo diferente de los tres barrigones de Concepción-Estación, cuya historia se ha descrito en este artículo. Sus contrapartes más próximas se encuentran en otros sitios de Escuintla. Cabe añadir que Rodas (1993) reportó otro barrigón, fragmentado, que se localizó en el anexo El Colorado de la finca Concepción. Es probable que provenga de otro sitio, aún desconocido, en la antigua propiedad del barón du Teil.
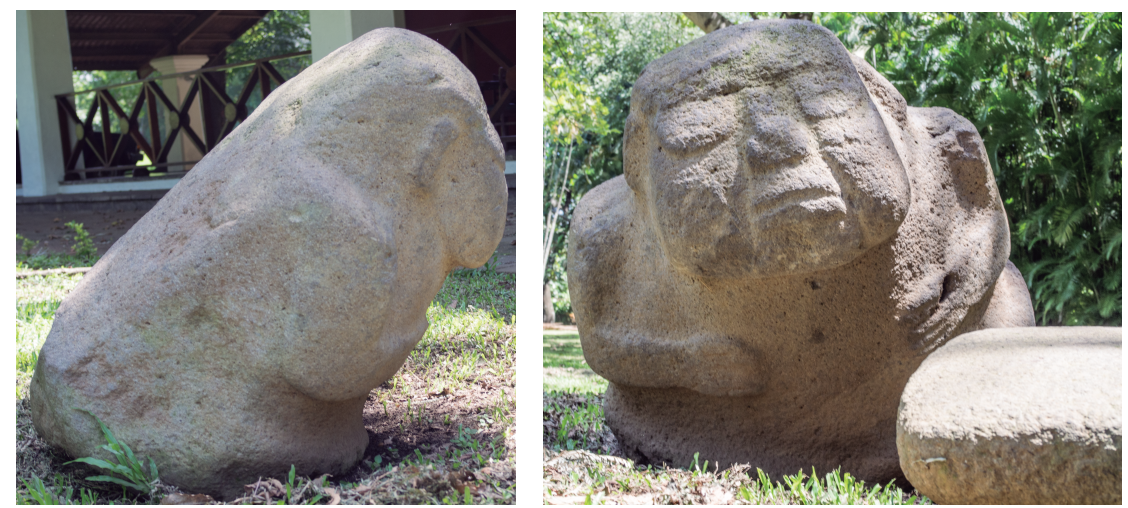

Figura 8. Monumento 1 de Concepción-Cementerio, Escuintla. Vista frontal y lateral. Fotografías: Oswaldo Chinchilla Mazariegos.
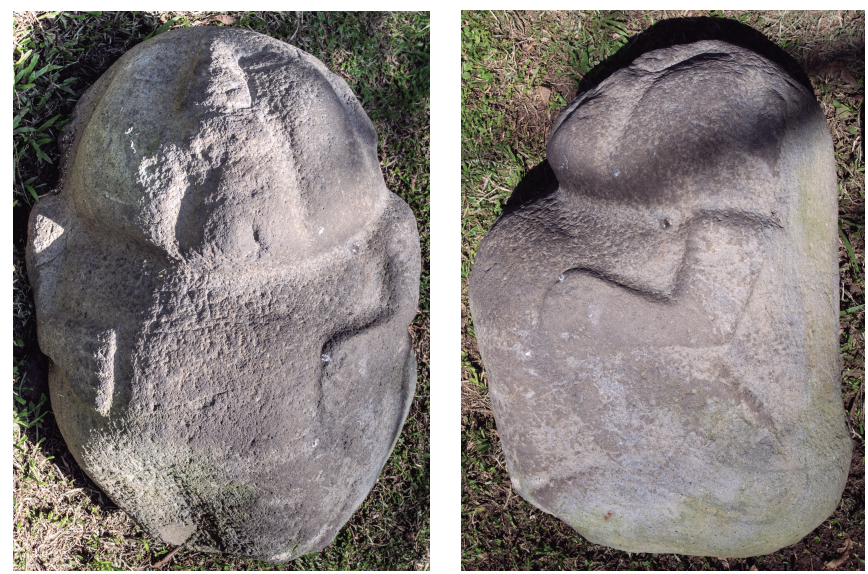

Figura 9. Monumento 4 de Concepción-Cementerio, Escuintla. Vista frontal y lateral. Fotografías: Oswaldo Chinchilla Mazariegos. 


\section{Colofón}

Quizá por sus formas elementales, los barrigones han resultado ser objeto de fascinación para los observadores modernos. Los volúmenes claros y los trazos simples que delinean el rostro y los miembros son claramente comprensibles. ¿Y quién deja de ver elementos de su propia naturaleza reflejada en el reposo pétreo de un barrigón? No es extraño que los barrigones —en especial los de Monte Alto- se cuenten en la actualidad entre los restos arqueológicos más distintivos de la Costa Sur.

Los de Concepción fueron arrancados de su contexto original en fecha temprana. Embarcados entre sacos de café, primero en el recién inaugurado ferrocarril y luego en los barcos de vapor que integraron a Guatemala en el comercio internacional, rodearon el cabo de Hornos con destino a los puertos de Francia y Alemania, y de allí, por vía férrea, arribaron a sus destinos respectivos. Quedaron disociados entre sí y separados de sus contextos originales, al punto que se llegó a olvidar su procedencia. Justo es reconstruirla y ponerlos en valor nuevamente como testimonios del arte, la religión y la vida de los antiguos habitantes de Escuintla.

Poco se conoce sobre ellos. A pesar de su importancia como un corredor natural hacia el valle de Guatemala, el entorno de la moderna cabecera departamental de Escuintla no ha sido objeto de estudios arqueológicos sustanciales. Más de 150 años después del descubrimiento de los barrigones, los terrenos de Concepción permanecen como una página en blanco en la arqueología de Guatemala. Ojalá algún día podamos conocer detalles sobre el sitio donde yacieron, a lo largo de dos milenios, los barrigones de Concepción.

\section{Reconocimientos}

La investigación documental en los archivos del Museo Etnológico de Berlín, Alemania, se realizó gracias a una beca otorgada a Oswaldo Chinchilla por la Oficina Alemana de Intercambio Académico (DAAD) en 1995. Durante ese periodo se contó con el apoyo incondicional del personal de ese museo, en especial la Dra. Marie Gaida, quien también facilitó la obtención de fotografías de los dos barrigones que pertenecen a esa colección. En Francia, contamos con el apoyo de Marie-Hélène Thiault del Museo de Saint-Germain-en-Laye, Alain Prévet de los Archivos del Museo del Louvre, Jean-Jacques Charpy del Museo de Épernay y Martine Moinot para la traducción de textos. Agradecemos a Bárbara Arroyo y Edgar Carpio por su colaboración en esta investigación y a Regina Wagner Henn por su autorización para reproducir la fotografía del barón du Teil, tomada de su valioso estudio sobre la historia del café en Guatemala. Asimismo, agradecemos a la empresa Pantaleón S.A. que facilitó el estudio de las esculturas de ConcepciónCementerio. 


\section{Bibliografía}

Baring-Gould, Sabine

1897 The Life of Napoleon Bonaparte. Londres: Methuen \& Co.

Bastian, Adolf

1878 Ein Jahr auf Reisen. Kreuzfahrten zum Sammelbehuf auf Transatlantischen Feldern der Ethnologie. Die Culturländer des Alten America, vol. 1. Berlín: Weidmannsche Buchhandlung.

1882 Steinsculpturen aus Guatemala. Berlín: Königliche Museen zu Berlin.

Baye, barón Joseph de

1880 L'Archéologie Préhistorique. París: Ernest Leroux.

1893 Industrial Arts of the Anglo-Saxons. Londres: S. Sonenschein \& Co.

Bergen, Werner von y S. J. Smith

1875 Passive Verb of the Thai Language, by F. L. Werner von Bergen, Consul for the German Empire, with the Siamese Verb, and Vocabulary of the Words Used in these Notices, by Rev. S. J. Smith, A. M. S. Bangkok: J. Smith Place.

Beuchat, Henri

1912 Manual d'archéologie américaine: Amérique préhistorique, civilisations disparues. París: Picard et Fils.

Congrés International des Américanistes

1886 Congrés International des Américanistes, sixième session, Turin. Châlons sur Marne: Martin Frères.

Chinchilla Mazariegos, Oswaldo

1996a “'Peor es Nada': El origen de las esculturas de Cotzumalguapa en el Museum für Völkerkunde, Berlin”, Baessler-Archiv, Neue Folge, 44: 295-357.

1996b "Settlement Patterns and Monumental Art at a Major Precolumbian Polity: Cotzumalguapa, Guatemala", tesis para obtener el grado de Philosophy Doctor, Vanderbilt University. Ann Arbor: University Microfilms International.

2001-02 "Los barrigones del sur de Mesoamérica", Precolombart, 4/5: 9-23.

2012 Cotzumalguapa, la ciudad arqueológica: El Baúl-Bilbao-El Castillo. Guatemala: F\&G Editores.

2016 “Just and Patriotic: Creating a National Museum in Guatemala (1831-1930)", Museum History Journal, 9: 60-76. DOI: 10.1080/19369816.2015.1118255

Demarest, Arthur, Roy Switsur y Rainer Berger

1982 "The Dating and Cultural Associations of the 'Potbellied' Sculptural Style: New Evidence from Western El Salvador", American Antiquity, 47: 557-571. DOI: $10.2307 / 280235$

Du Teil, Oscar y Xavier du Teil

1866 "Cultivo del cafeto y beneficio de su fruto", La Sociedad Económica, 1: 76-98. 
Fauvet-Berthelot, Marie-France

1992 “Henri Lehmann (1901-1991)", Journal de la Societé des Américanistes, 78: 179185.

Fischer, Manuela

2007 "Adolf Bastian's Travels in the Americas (1875-1876)", Adolf Bastian and His Universal Archive of Humanity: The Origins of German Anthropology, pp. 191206, Manuela Fischer, Peter Bolz y Susan Kamel (eds.). Hildesheim: Georg Olms Verlag.

García, Edgar Vinicio

1997 "Excavaciones en el acceso a la terraza 3, Abaj Takalik", X simposio de investigaciones arqueológicas en Guatemala, pp. 167-191, Juan Pedro Laporte y Héctor Escobedo (eds.). Guatemala: Instituto de Antropología e Historia, Asociación Tikal.

Girard, Rafael

1962 Los mayas eternos. México: Antigua Librería Robredo.

1968 La misteriosa cultura olmeca: últimos descubrimientos de esculturas pre-olmecas en Guatemala. Guatemala: Imprenta Eros.

Guernsey, Julia

2012 Sculpture and Social Dynamics in Preclassic Mesoamerica. Cambridge: Cambridge University Press.

Huyghe, René

1957 L'Art et l'Homme. Tomo I. París: Larousse.

Jell-Bahlsen, Sabine

1985 "Ethnology and Fascism in Germany", Dialectical Anthropology, 9: 313-335.

Jougla de Morenas, Henri

1949 Grand Armorial de France. Catalogue général des armoiries des familles nobles de France. París: Société du Grand armorial de France.

Krickeberg, Walter

1950 Mittelamerikanische Denkmäler. Berlin: Museum für Völkerkunde.

Le Goff, Armelle y Nadia Prevost Urkidi

2009 Commission de l'exploration scientifique du Mexique (1862-1893) F/17/2909 à 2914/3. Répertoire méthodique et semi-analytique. Archives Nationales, París. $<$ http://www.archivesnationales.culture.gouv.fr/chan/chan/fonds/edi/sm/F/ F17\%202909-2914.pdf> [Consultado el 1 de octubre de 2012].

Luján Muñoz, Luis

1973 "El primer Museo Nacional de Guatemala (1866-1881)", Anales de la Sociedad de Geografía e Historia de Guatemala, 46: 173-189.

CHINCHILla - FAUVET / EL PERIPLO DE LAS ESCULTURAS DE CONCEPCIÓN, ESCUINTLA 
Musée de l'Homme

1965 Chefs-d'œuvre du Musée de l'Homme. París: Caisse Nationale des Monuments Historiques.

Parsons, Lee A.

1969 Bilbao, Guatemala: An Archaeological Study of the Pacific Coast Cotzumalhuapa Region. Volumen 2. Milwaukee: Milwaukee Public Museum.

1986 The Origins of Maya Art: Monumental Stone Sculpture of Kaminaljuyu, Guatemala, and the Southern Pacific Coast. Washington, D.C.: Dumbarton Oaks.

Parsons, Lee A. y Peter S. Jenson

1965 "Boulder Sculpture on the Pacific Coast of Guatemala", Archaeology, 18: 132144.

Penny, H. Glenn

2002 Objects of Culture: Ethnology and Ethnographic Museums in Imperial Germany. Chapel Hill: University of North Carolina Press.

2003 "Bastian's Museum: On the Limits of Empiricism and the Transformation of German Ethnology", Worldly Provincialism: German Anthropology in the Age of Empire, pp. 86-126, H. Glenn Penny y Matti Bunzl (eds.). Ann Arbor, Michigan: The University of Michigan Press.

Reinach, Salomon

1917 Catalogue ilustré du Musée des Antiquités Nationals au château de Saint-Germainen-Laye. París: Ernest Leroux.

1926 Catalogue ilustré du Musée des Antiquités Nationals au château de Saint-Germainen-Laye. París: Musées Nationaux.

Révérend, Albert

1902 Titres, annoblissements et pairies de la restauration, 1814-1830. Tomo 2. París: Honoré Campion Libraire.

Rodas, Sergio

1993 "Catálogo de barrigones de Guatemala", $U$ tz’ib, 1 (5): 1-36.

Schoonover, Thomas

1998 Germany in Central America: Competitive Imperialism, 1821-1929. Tuscaloosa: The University of Alabama Press.

Seler, Eduard

1901 Die Ausgrabungen am Orte Haupttemples in Mexico. Wien: Mittheilungen der Anthropologischen Gesellschaft.

Shook, Edwin M.

1975 "Field Notes on a Trip to the South Coast of Guatemala with Jack Gillin, June 1942", Papers on the Xinca of Eastern Guatemala, Lyle Campbell et al. (eds.). Columbia: Museum of Anthropology, University of Missouri. 
Sociedad Española para la Acción Cultural Exterior

2003

El país del quetzal: Guatemala maya e hispánica. Madrid: Sociedad Española para la Acción Cultural Exterior.

United States Congress House

1898 Papers Relating to the Foreign Relations of the United States, with the Annual Message of the President Transmitted to Congress. December 6, 1897. Washington D.C.: Goverment Printing Office.

Wagner, Regina

2001 The History of Coffee in Guatemala. Bogotá: Villegas Editores.

Wikipedia

2016

Werner von Bergen, Wikipedia, <http://de.wikipedia.org/wiki/Werner von Berger $>$ [Consultada el 6 de junio de 2017].

Woodward, Ralph Lee

1993 Rafael Carrera and the Emergence of the Republic of Guatemala, 1821-1871. Athens: University of Georgia Press. 
Documentos de archivo

Archivo del Ethnologisches Museum, Berlín, Alemania

Acta Betreffend die Steinsculpturen von Santa Lucia Pars. I B. Litt E. Sin paginación.

Archivo del Museo de Saint-Germain-en-Laye, Francia

DT $38-60$

Musée du Quai Branly, París

Inventario PPOO98762

Archivo des Musées Nationaux, París

G8 1907 “Donation Baron de Baye au Musée de Saint-Germain” 


\section{Anexo I}

\section{Carta de Werner Von Bergen a Adolf Bastian [Extracto]}

Guatemala, 17 November 1886

[Se omitió el primer párrafo de la carta, que no es relevante para el tema]

Baron du Theil ist bereit die auf einer seiner Besitzungen befindlichen fünf altindianischen Tumuli, aus welchen die dem Königlichen Museum übersandte Vogelstatue stammt und in deren Nähe die beiden übersandten großen Steinidole gefunden worden, zur Ausbeute zu überlassen.

Vielleicht wurde es der Mühe verlohnen, etwa 1500 Mark vorschußweise zur Öffnung des Haupt Tumulus anzuweisen. Da die Besitzung an der Eisenbahn liegt, würde ich selbst in der Lage sein —ohne Beihülfe eines Ingenieurs - die ersten Arbeiten anzuordnen und deren Weiterfuihrung durch das Beamtenpersonal des Baron du Theil überwachen zu lassen.

der Kaiserliche Minister-Resident

Werner von Bergen

Traducción:

El barón du Theil está listo para permitir la explotación de los cinco túmulos de los antiguos indios que se ubican en una propiedad suya, de los cuales proviene la estatua del pájaro enviada al Museo Real, y en cuya proximidad fueron encontrados los dos grandes ídolos de piedra enviados.

Quizás valga la pena adjudicar unos 1500 marcos como anticipo para abrir el túmulo mayor. Puesto que la propiedad queda sobre la línea del tren, podría estar yo mismo en el lugar - sin la ayuda de un ingeniero- para coordinar los primeros trabajos, y dejar su continuación al cuidado del personal del barón du Theil.

el Ministro-Residente Imperial

Werner von Bergen ${ }^{9}$

\section{Anexo II}

\section{Carta del barón de Baye al barón du Teil}

A Monsieur le Baron du Teil à Guatemala 3 mars 85

Cher Monsieur,

J'ai eu l'honneur de vous exposer dans une précédente lettre, tout ce que l'Amérique centrale offrait d'intérêt pour les études archéologiques. Les ruines qui s'y rencontrent sont d'inépuisables sujets de recherches. La matière est encore peu connue, c'est vous dire en un mot tout le prix que j'attache aux renseignements qu'il vous sera possible de me faire

\footnotetext{
${ }^{9}$ Traducción de Oswaldo Chinchilla Mazariegos y María Gaida.
} 
parvenir. Je serai fort heureux d'avoir l'idole que vous avez la bonté de me proposer. Les objets en pierre dont vous disposez seront pour moi d'utiles points de comparaison. Vos visites à l'antiquaire auront certainement pour résultat de connaître les provenances et les gisements. Je ne réitère pas ce que je vous disais naguère, tous les documents que vous me transmettrez auront une grande utilité pour moi.

\section{Traducción:}

Al señor barón du Teil en Guatemala, 3 de marzo de 1885

Estimado señor,

En una carta anterior, he tenido el honor de exponerle todo lo que América Central tenía de interés para los estudios arqueológicos. Las ruinas encontradas allá son temas inagotables de investigación. La materia todavía es poco conocida, lo que le dice en una palabra el precio que otorgo a las noticias que a usted le será posible enviarme. Me hará muy feliz recibir el ídolo que usted tiene la bondad de proponerme. Los objetos de piedra de que usted dispone serán para mí puntos de comparación útiles. Sus visitas al anticuario [sitio arqueológico] seguramente tendrán como resultado conocer las procedencias y los yacimientos. No reitero lo que ya le decía antes: todos los documentos que usted me transmita tendrán una gran utilidad para mí. ${ }^{10}$

\section{Anexo III}

\section{Cartas del barón de Baye, dirigidas a Adolf Bastian, director del Real Museo Etnográfico de Berlín}

Primera carta

Château de Baye, à Baye-Marne, France

8 Avril 1886

Monsieur le Directeur,

Un de mes amis, Monsieur le Baron du Teil, qui habite Guatemala vient de m'envoyer une divinité indienne qui a été trouvée dans une de ses plantations (La Concepcion). De pareilles divinités ont été offertes au gouvernement allemand par Monsieur le Baron du Teil. Je sais que ces monuments intéressants figurent dans un de vos remarquables musées. Monsieur le Baron von Bergen, ministre d'Allemagne, qui s'occupe avec zèle et succès de ces antiquités a certainement recueilli de précieux documents sur les divinités que vous possédez maintenant. Je vous serais très reconnaissant, Monsieur le Directeur, si vous vouliez pousser la bonté jusqu'à me donner les renseignements que vous possèdez sur ces antiques idoles et les interprétations dont elles ont été l'objet.

\footnotetext{
10 Traducción de Marie-France Fauvet-Berthelot.
} 
La divinité indienne qui m'a été envoyée, a la même provenance que celles qui vous ont été offertes par Monsieur le Baron du Teil. Lorsque le moment sera venu, je me ferai un devoir de vous communiquer les résultats de mes recherches et de vous envoyer un dessin, si vous en avez le désir.

Veuillez agréer, Monsieur le Directeur, l'hommage de mes sentiments le plus distingués.

Baron J. de Baye

\section{Traducción:}

Castillo de Baye, en Baye-Marne, Francia

8 de abril de 1886

Señor director,

Uno de mis amigos, el señor barón du Teil, que habita en Guatemala, me ha enviado una divinidad indígena que ha sido encontrada en una de sus plantaciones (La Concepción). Parecidas divinidades han sido ofrecidas al gobierno alemán por el señor barón du Teil. Yo sé que esos interesantes monumentos figuran en uno de vuestros notables museos. El señor barón von Bergen, ministro de Alemania, quien se ocupa con celo y éxito de estas antiguiedades, ciertamente ha reunido documentos preciosos sobre las divinidades que usted posee ahora. Yo le estaría muy agradecido, señor director, si usted tuviera la bondad de darme la información que usted posee sobre estos antiguos ídolos y las interpretaciones de que han sido objeto.

La divinidad indiana que me ha sido enviada tiene la misma procedencia que aquellas que le han sido ofrecidas por el señor barón du Teil. Cuando llegue el momento, será mi deber comunicarle los resultados de mis investigaciones y enviarle un dibujo, si usted lo desea.

Sírvase aceptar, señor director, el homenaje de mis sentimientos más distinguidos.

Barón J. de Baye ${ }^{11}$

Segunda carta, acompañada con un dibujo de la escultura

\section{0 août 1886}

Monsieur le Directeur,

J'ai reçu avec la plus grande satisfaction la brochure relative aux pierres sculptées de Guatemala. Je vous en mis très reconnaissant et vous prie de daigner agréer l'expression de mes remerciements.

Les pierres sculptées qui font l'objet de votre travail ne paraissent pas offrir les mêmes caractères que l'idole indienne que j'ai reçue.

\footnotetext{
11 Traducción de Oswaldo Chinchilla Mazariegos.
} 
Si mes renseignements sont exacts, vous devez avoir des blocs sculptés se rapprochant celui que je viens de recevoir récemment. J'ai l'honneur de vous en donner un croquis en vous priant de me faire savoir si vous trouvez de la ressemblance avec ce que vous possédez de pareille provenance.

Veuillez agréer, Monsieur le Directeur, l'hommage de mes sentiments les plus distingués.

Baron J. de Baye

au Château de Baye, à Baye Marne, France.

\section{Traducción:}

20 de agosto de 1886

Señor director,

He recibido con la mayor satisfacción el folleto relativo a las piedras esculpidas de Guatemala. Le quedo muy reconocido y le ruego dignarse recibir la expresión de mis agradecimientos.

Las piedras esculpidas que fueron objeto de vuestro trabajo no parecen ofrecer las mismas características que el ídolo indiano que yo he recibido.

Si mis noticias son exactas, usted debe tener unos bloques esculpidos que se asemejan al que yo he recibido recientemente. Tengo el honor de enviarle un croquis, rogándole que me permita saber si usted encuentra un parecido con los que usted posee, de parecida procedencia.

Sírvase recibir, señor director, el homenaje de mis sentimientos más distinguidos.

Barón J. de Baye

En el Castillo de Baye, en Baye Marne, Francia. ${ }^{12}$

12 Traducción de Oswaldo Chinchilla Mazariegos. 